\title{
A Socio-technical experiment with a resource efficient Product Service System
}

Maurizio Catulli - Business School, University of Hertfordshire, Hatfield, Herts AL10 9AB, m.catulli@herts.ac.uk, +44 (0) 1923254146

\section{Liridona Sopjani - Department of Integrated Product Development, KTH, SE-100 44} Stockholm, Sweden

Nick Reed - School of Life and Medical Sciences, University of Hertfordshire, Hatfield, Herts AL10 9AB

John Tzilivakis - School of Life and Medical Sciences, University of Hertfordshire, Hatfield, Herts AL10 9AB

Andrew Green - School of Life and Medical Sciences, University of Hertfordshire, Hatfield, Herts AL10 9AB

This paper describes a socio-technical experiment relating to a sustainable innovation project conducted in a protected niche or "living lab" and evaluates the ability of the experiment to generate learning and strategic direction. The study focused on a Product Service System (PSS) for renting infant mobility products to consumers. A PSS is a resource efficient system of products and services supported by networks and infrastructure. In the experiment, refurbished products were rented to 1044 families, with some products being reutilized three times. Learnings were generated through five stages: combining competences and resources, steering and facilitating change, engaging users at early stages, offering users opportunities to modify practices through trial and capturing and mediating mutual learning through knowledge co-creation. The observed environmental benefits included reduction of particulate plastic matter released into the environment and transportation of materials. Considerable barriers to the implementation of the PSS in the open market were identified, including attrition through loss or damage, product liability and consumer distrust in sharing products due to fear of contagion.

\section{Key words}

Infant Mobility Products; Product Service System; Resource Efficiency; Socio-Technical Experiments; Strategic Niche Management 


\section{A Socio-technical experiment with a resource efficient Product Service System}

\section{Introduction}

Production and consumption of goods depletes natural resources, exhausts materials and generates waste, $\mathrm{CO} 2$ emissions and plastic pollution (Haward 2018). One way to address these issues is the transition to more sustainable ways of consumption that minimise waste and support recovery, reuse and recycling of materials and resources. Product Service Systems (PSS) are offerings that can support these objectives. PSS offer opportunities to access products at reduced costs (Schmidt-Costa et al. 2019), lower material intensity and greater resource efficiency than would be the case with traditional modes of consumption. PSS are defined as "systems of products, services, networks of actors and supporting infrastructure developed to be competitive, satisfy customers and be more environmentally sound that traditional business models" (Mont 2002, 239). Examples of PSS include car sharing (Cherubini et al. 2015) and bicycle sharing offerings such as the Vélib system in Paris (Zademach and Musch 2018).

Consistent with a circular economy (Tukker 2015), PSS are potentially more resource efficient than conventional ways of supplying products because they extend suppliers' responsibility beyond the end of the usual product life cycle and promote recovery of resources and reutilization of products (White et al. 1999). Tukker (2015) classifies PSS as being:

- Product orientated - services are added to products owned outright by customers, e.g. remote printer cartridge ink use monitoring, automatic reordering and delivery

- Use orientated - customers use products without owning them, e.g. cars accessed through car clubs and leasing arrangements

- Result orientated - customers purchase results/ outcomes, e.g. thermal comfort in buildings

Despite these apparent benefits and resource efficiency PSS are not widely implemented (Vezzoli et al. 2015), particularly in consumer markets (Tukker 2015). This may be due to issues ranging from perceived lack of safety of refurbished products (Catulli and Reed 2017), to lower ability to deliver symbolic value than products owned outright (Catulli et al. 2017) and their inability to grant the control over products that consumers desire (Tukker 2015).

Indeed, PSS offerings have faced "real world" challenges and sometimes "unfavourable attention' (Booth 2016). In Manchester and Newcastle, the bicycle sharing company Mobike 
suffered high levels of vandalism and theft (Pidd 2018) and experiences such as these have associated bicycle sharing with financial risk (Hern and Topham 2018). The current

Coronavirus pandemic (Leach et al. 2010) may be an existential threat to offerings such as PSS because fear of cross-infection may deter consumers from using offerings that involve the use of shared assets (Harrabin 2020). Indeed, companies such as AirBnB and the electric car club e-carclub have had to interrupt their services for these reasons (ecarclub.co.uk 2020). Such challenges to PSS implementation highlight the need to ensure that PSS research explores real world problems that PSS implementation may encounter in competitive markets (Ceschin 2013). The study reported in this paper sought to investigate these problems through a socio-technical experiment that was designed according to the principles of Strategic Niche Management (SNM) (Susur et al. 2019) in simulated "open market" conditions.

A Government funded small-scale research project entitled 'Re-Engineering Business for Sustainability' (REBUS) implemented a PSS designed to enhance resource productivity. The PSS related to renting infant mobility products such as pushchairs and infant car seats.

Following Mont et al. (2006), it was considered that infant mobility products were suitable for a PSS because they are (1) durable with a typical life expectancy of 10 years but (2) in practice they may only be used by their owners for 1-3 years (i.e., because the child who is using the product grows out of it) with consequent waste of resources and materials. These two features indicate that such products can be refurbished and reused as part of a PSS. Refurbishment can be defined as "the action of giving back a function or specific use" to equipment, where "some materials or systems can vary" from their original state (Vilches et al. 2017,288 ) in order to reuse that equipment. Recycling, reusing and refurbishing products are key aspects of PSS implementation (Wellsandt et al. 2016, Fargnoli et al. 2018). Through refurbishing, PSS may promote closed loop systems (Sinha et al. 2016) which enable recovery and reuse of at least some of the components and enhance resource productivity (Laurenti et al. 2015). However, refurbished products provided through PSS need to have new-like quality and warranties (Sundin et al. 2009). From the operational point of view, it is also important to establish what products should be refurbished and which should be disposed of (Fargnoli et al. 2018). The PSS in this project was designed so that the products could be refurbished after each use and used by another set of parents, to maximise resource productivity.

Despite extensive research on SNM, little work has been done to describe activities, challenges, and experiences of developing solutions like PSS experiments that have been run in protective niches (Sengers et al. 2019). To describe the socio-technical experiment we drew on a framework proposed by Sopjani et al. (2017), which describes the activities that 
take place in experiments conducted in strategic niches, or "living labs". The research had the following objectives:

1. To investigate consumer acceptance of this PSS

2. To investigate how the learning processes on design and implementation of the PSS could be structured in a socio-technical experiment

3. To explore issues that would be likely to arise in the event of large-scale implementation of the PSS in the open market.

The paper discusses the concepts of SNM and socio-technical experiments, describes the methods used in the study, presents and discusses the findings and draws conclusions.

\section{Theoretical Framework}

Strategic Niche Management has been defined as the "creation, development, and controlled phase-out of protected spaces for the development and use of promising technologies by means of experimentation" (Kemp et al. 1998, 186). A niche is a space "isolated" from the influence of the dominant socio-technical regime (Ceschin 2013), where radical innovations introduced by small networks of dedicated actors (Geels and Schot 2007) can be developed and tested.

A niche can be compared to a 'living lab' - a user-centric innovation milieu built on everyday practice and research in real-life contexts, with an approach that facilitates user influence in open and distributed innovation processes (Bergvall-Kåreborn et al. 2009). An example of a living lab is the Smart Mobility Unit (University of Hertfordshire 2020), where developing innovations such as electric car and bicycle sharing are offered to limited user groups such as staff and students, whilst the innovations are being researched.

The concept of strategic niche originated within the so-called Multi-Level Perspective (MLP). The MLP is a three level framework, which views sustainability transitions as multidimensional, non-linear processes that result from the interplay of developments at three analytical levels (Geels 2002):

1. the socio-technical landscape, describing the macro features of socio-technical systems

2. the socio-technical regime, describing the micro features including interactions between technology, policy (power and politics), economics (business and markets) and culture (discourse and public opinion) which enable sustainability transitions (Geels 2011). 
3. Socio-technical niches, interacting with regimes on multiple dimensions (e.g., markets, regulations, cultural meanings, technologies).

The MLP focuses on the diverse actors involved in transitions, their strategies, resources, beliefs and interactions that can shape socio-technical transitions (Geels 2002) and enable understanding of the dynamics of structural change and the obduracy of current technologies within stabilized systems.

At the niche level, SNM aims at finding out why promising sustainable technologies fail to bridge the gap between Research \& Development and market introduction (Schot and Geels 2008) and to describe the technological innovation processes involved, including interactions of technologies with users and society within social structures. SNM offers an alternative view to narrow, linear, top-down approaches toward innovation (lbid.), such as carbon accounting software to address Government policy on carbon taxation. It is both a research model and a policy tool (Ceschin 2013) for achieving an integrated analysis of the development, management and diffusion of radically new sustainable technologies (Schot and Geels 2008). SNM strives to understand processes of radical change of existing practices, products, technologies and organizations that shape and stimulate transitions toward sustainability (Ibid.). In these interactions, actors within niches establish and draw upon rules for their practices, such as legally binding contracts or regulations.

A core tenet of SNM is that experiments can be conducted on innovations within niches serving as 'proto-markets' prior to exposing innovations to real-world conditions step-by-step to evaluate their fitness (Ceschin 2013) when design and user demands have been stabilised (Schot and Geels 2008). An experiment is an initiative which tests innovations whilst unencumbered by "the material, institutional and cognitive obduracy of incumbent sociotechnical systems central to our way of life." (Sengers et al. 2019, 161). Through experimentation, SNM aims to learn whether new technologies are desirable and applicable (Schot and Geels 2008). SNM attempts to generate knowledge in interactions with users throughout innovation development processes, to learn about constraints and requirements, specify technologies and profile consumers, while fostering institutional connections and adaptations (Hoogma et al. 2002). Processes that align social and technical aspects may facilitate technical innovation and bring about new and more sustainable practices because of new experiences and practical learnings by doing and reflecting (Schot and Geels 2008). Despite these opportunities, the transformative power of experiments is limited, unless they are linked to long-term strategies for structural change involving key actors in the process e.g. policy makers (Sengers et al. 2019). 
The core processes that protect niche experiments are (Ibid.):

- Shielding, which holds off in active or passive ways the competitive pressures innovations are subjected to in open markets

- Nurturing, supports the development of path-breaking innovation and

- Empowerment, which makes niche innovations competitive vis-à-vis regimes.

Two empowerment patterns, fit-and-conform, the development of niche innovations to fit existing rules and institutions and stretch-and-transform, the adjustment of rules and institutions to suit niche innovations, describe possible relations between niche innovations and existing regimes (Köhler et al. 2019).

In a niche, the enrollment of diverse actors in experiments such as 'regime outsiders' from other industries and academia (Van De Poel 2000) and 'frontrunner actors', individuals operating within existing structures but with a certain level of independence, e.g. opinion makers, trendsetters and generalists with overview and social authority, expands the resource base and the network (Geels 2011). The challenge is to coordinate this diversity. In niches, actors need to align their roles and expectations to avoid 'hype-disappointment cycles'. Hype may trigger actors to engage in a race to be the first to develop and commercialize an innovative technology but this may engender disappointment when expectations are not met, which can inhibit innovation (Bakker and Budde 2012). Following Sopjani et al. (2017), this paper tests a framework constituted by these niche activities:

1. Combining competences and resources between diverse actors

2. Steering and facilitating to enable co-creation between actors

3. Engaging users at early stages before fully developing the innovation, to define markets better and to understand applicability early on

4. Offering users opportunities to modify practices through trial of offerings

5. Capturing and mediating mutual learning through collective knowledge co-creation.

The research describes the learning, interaction, rulemaking and strategic direction (Loorbach and van Raak 2006) generated through these activities and how these can assist the development of niche experiments into market worthy innovations (Caniëls and Romijn 2008). The next section describes methods used. 


\section{Materials and methods}

REBUS adopted Action Research (AR), a flexible research strategy (Lewin 1947) to "study social systems by changing them" (Heale 2003,4). AR consists of implementing a project with the aim of testing changes in practices and evaluating effects in a real world context (Argyris and Schön 1989). Although the design of the project as a strategic niche experiment was initially not made explicit, the REBUS project conforms to Caniglia et al.'s (2017) typology of niche experiments. AR supports multiple methods for collecting data (Heale 2003), such as expert workshops - a type of elite group interview that aims to capture the opinions and thoughts of experts (Brinkmann and Kvale 2015) and observation. The REBUS niche involved:

- a university,

- a North American infant mobility products manufacturer,

- a logistics company,

- a parental charity and

- participants drawn from the members of the charity.

AR proceeds through "learning cycles" of implementation in six stages: diagnosing, planning, implementing, evaluating, learning and replanning (Glasson et al. 2008) through regular meetings. A project steering committee was established for REBUS and the committee included representatives from all the collaborating parties. The steering committee meetings were a research method as well as a management tool. The aim of the meetings was to collect qualitative and quantitative data on the performance of the project and on the interaction and collaboration between research partners. The workshops were semistructured with agendas aimed at running the project. Meetings were not audio recorded (for commercial confidentiality) but the researchers took extensive notes. Observation was conducted and recorded on field notes.

The university conducted a simplified Life Cycle Assessment (LCA) for car seats to estimate environmental benefits of the PSS. The LCA focussed on the resources, energy and emissions associated with the manufacture and transport (assembly and refurbishment processes; retail, use and end of life phases were scoped out, as they were either negligible or not relevant for the comparison to conventional systems). The approach followed LCA processes defined by ISO 14040 \& 14044 as far as that was possible given the data available. The manufacturer provided primary data on materials and components used in the car seats. Data on emissions, resource use and impacts came from secondary sources including the European reference Life Cycle Database (JRC 2016) and bespoke studies (IPCC 2006, Shen and Patel 2008, Turley et al. 2008, Beton et al. 2014, Dibdiakova and 
Timmermann 2014, Plastics Europe 2014). A key indicator for the performance of the PSS (for resource use, emissions and impacts) is the incremental benefit per use, thus results are expressed per 2 uses or the difference per use (the functional unit). All impacts were normalised by expressing values as a percentage of the impact of the average person in the European Union (Sala 2015).

Two semi-structured expert workshops were conducted at the end of the project to collect qualitative and quantitative data from the partners in order to summarize learning outcomes. These two workshops involved managers of the manufacturer, the logistics company, the parental charity and the researchers. The interview guides used in the workshops included themes connected with SNM. Data were digitally recorded, transcribed and analysed in NVivo using a flexible template approach (cf. Miles and Huberman 1994). The template used for the analysis was structured around the niche activities listed in Section 2. The paper uses these activities as a framework to present the findings.

\section{Findings}

This section reports the results of the analysis of data from the periodic evaluation meetings and the final workshops described in section 3. The analysis is conducted through an SNM framework. The narrative uses certain terms to describe the collaborators in the project. Because of the inclusion of product and service elements in PSS, in this article the term 'PSS provider' means the collaborator who interfaces with users of the products - in this case the parental charity. We use the term "manufacturer" to describe the supplier of the products. The users were members of the parental charity, which fostered a sense of belonging to a community that facilitated acceptance of innovative offerings (Cova and Cova 2002).

Users were accessed through a database owned by the charity. This shielded the project from competition, as the charity enjoyed the trust of the users. The REBUS PSS started in January 2014 (when the parental charity website started to promote the rental service) and it lasted for approximately two years.

\subsection{Combination of competences and resources}

The resources involved in the project included (1) products accessed through the PSS, (2) the user database, (3) a repair and refurbishing workshop (belonging to the manufacturer), (4) people and phone lines to interact with users provided by the manufacturer and the provider, and (5) logistics assets (warehouse and vehicles) owned by the logistics company. Finally, shared competences and resources included the intellectual assets of the University, 
e.g., design, social sciences and environmental management assets, which supported the implementation and monitoring of the experiment.

The REBUS project rented out infant products that were not specifically designed for a PSS. The manufacturer provided these products free for the project with the hope of recovering their costs from the rental income. This nurtured the innovation by taking up some of the risk of the project. Product examples are shown in Figures 1 and 2.

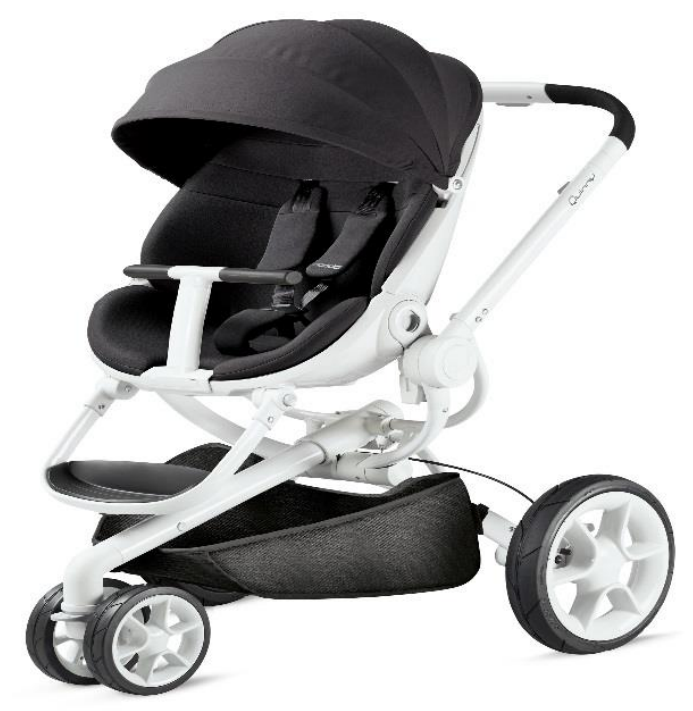

Figure 1 Type of stroller offered in the PSS

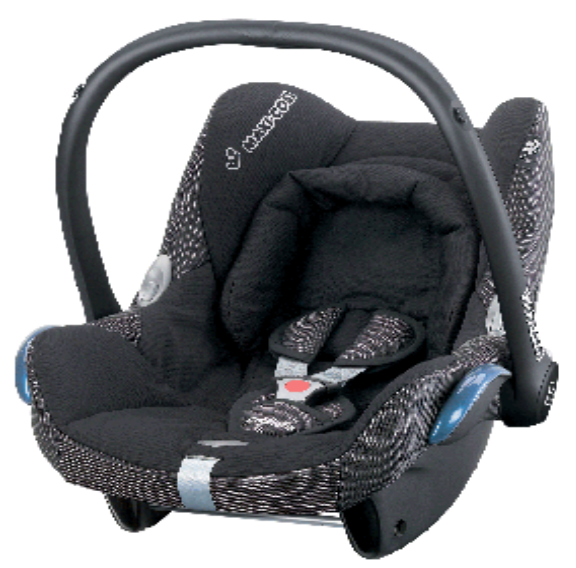

Figure 2 Type of car seat

At the time of the implementation of the REBUS project, hiring (renting) of goods for periods longer than three months to the same consumer constituted a regulated consumer hire business and the operation of such a business required a Category B Consumer Credit Licence (CCL) (OFT 2008). However, the research partners designed the offering so that users would pay for the service in advance with a single payment, so that the provider did not need to acquire a CCL. 
From the outset, the researchers designed the REBUS offering in collaboration with the manufacturer, to include full inspection and refurbishment processes, performed at the manufacturer's workshop. For a car seat, the refurbishing process included expert inspection of the harness system and the shell that absorbs impacts.

The research partners performed a number of back and front office processes associated with service delivery. The partners managed these processes manually because of the small scale of the project. These functions required the co-ordination of (1) the charity that contributed customer interface, (2) the manufacturer and (3) the logistics company, which provided the remaining functions, storage and logistics. The research partners thought it was necessary to perform these processes across the boundaries of different companies and this was a significant challenge when configuring a small-scale niche experiment. Here the research partners and DEFRA nurtured the innovation respectively through contribution in kind and funding.

REBUS achieved access to users with the help of the provider. This organization provided the assets of customer knowledge, credibility, trustworthiness and a database for promotion of the PSS to users. The charity received a share of the rental income and REBUS allocated a portion of the grant to cover their costs.

The workshop participants expected a more direct rapport with customers to be a key benefit of implementing this PSS. Such a rapport facilitates better understanding of customer needs. Prior to the project, the provider did not have direct knowledge about consumers, because they sold products to specialist retailers who then sold them on to consumers. A more direct relationship with consumers is desirable because e.g., if parents usually need to buy a 'follow-on' car seat a few months after buying the first one, the provider can then identify who those customers are, so that they can offer appropriate products. An enhanced relationship management capability also benefitted the provider's marketing strategy and they gained a better understanding of database management.

\subsection{Steering and facilitating to enable co-creation}

The steering committee held eight quarterly "loop" meetings over the duration of the project to reflect and consolidate learning, assess progress and formulate strategies. At the meetings, the collaborative partners shared and discussed quantitative data, which they collected on an ongoing basis. These data included project performance indicators such as:

- $\quad$ sales volumes and trends 
- usage

- attrition

- pushchairs and car seats Life Cycle Analysis data.

These meetings enabled co-creation through sharing design and strategic knowledge. The discussions supported key decisions concerning PSS design, such as details of the rental agreement and avoiding the need to acquire a CCL. The co-creation activities also supported the design of the offering, which led to a selection of products to include in the PSS with the charge for leasing car seats and pushchairs for 6 months being considerably lower than their purchase price. Table 1 below compares prices for purchasing the products outright and for leasing them.

Table 1 PSS Vs traditional purchase comparison

\begin{tabular}{|l|l|l|}
\hline Item & $\begin{array}{l}\text { Lease Price } \\
(6 \text { months })\end{array}$ & $\begin{array}{l}\text { Outright } \\
\text { Purchase Price }\end{array}$ \\
\hline Quinny Moodd & $£ 144.00$ & $£ 600.00$ \\
\hline Foldable Carrycot & $£ 45.00$ & $£ 165.00$ \\
\hline Maxi-Cosi Cabriofix Car Seat & $£ 26.25$ & $£ 135.00$ \\
\hline Maxi-Cosi Pebble Car Seat & $£ 34.13$ & $£ 165.00$ \\
\hline Family Fix Base & $£ 44.63$ & $£ 165.00$ \\
\hline
\end{tabular}

Source: The Authors

The rental fee included delivery and collection of products. When the lease period ended (unless customers had renewed the lease), a courier would collect items for return to the manufacturer's warehouse, where providers could refurbish products and then supply them to the next customer.

\subsection{Engaging users at early stages of innovation}

Prior the implementation of REBUS, the researchers engaged users with a range of methods including focus groups and one to one interviews. Initially, managers thought that consumers would see leasing and renting as stigmatizing and damaging to the consumers' self-image, although they reported that their market research suggested that younger consumers were more likely to accept renting or leasing products than previous generations. As users were all members of the provider, they were easily accessible by the project but shielded from competition because of the proprietary nature of the database.

These engagements shed light on the applicability of the PSS. An unsurprising finding was that users want products that look brand new and attractive when they receive them even if 
they had gone through multiple prior uses. In addition, potential users were concerned about using refurbished pushchairs and car seats, which they thought previous users could have damaged or contaminated. Users were also concerned about renting because of possible penalties if they damaged products. These concerns were also revealed by survey of members of the parental charity (Catulli and Reed, 2017).

The fit-and-conform response to these concerns was the design of a quality assurance (QA) certification for the inspections described in section 4.1, consisting of a one-page certificate describing operations performed on products during refurbishment. The QA certification empowered users as they had a say in shaping the safety aspects of the PSS.

Some participants believed that the marketing communications, such as the parental charity's website, should have emphasized environmental protection more than financial savings to promote pushchairs and car seats for rent. The demographic group that the charity targets is probably the most likely to exhibit a 'green' purchasing behaviour but, conversely, they are also the people who may be more interested in status symbols and, therefore, possibly more likely to want to own products outright.

\subsection{Offering users opportunities to modify practices}

To advertise the PSS the provider e-mailed their membership with a link to the web site. Here the process of shielding was in evidence, as the database was the property of the provider so competitors could not access members. In the period between January 2014 and December 2015 (when the project concluded), a total of 892 physical products had been leased to parents, of which 827 were car seats and car seat bases and 65 were pushchairs. Several products were leased multiple times, so in total, 1044 "accesses to use"1 were achieved. Car seat leases represented by far the largest proportion of the total lease volume, with 923 accesses to 827 car seats/Isofix car seat base combinations. Pushchairs represented just $7 \%$ of the accesses. A possible explanation for this difference in performance is that users may have decided whether to rent products based on the ratio between cost and duration of use. Consumers may see an item, which is costly in relation to its period of use as more appropriate for renting than outright purchase. Indeed, the most successful car seats in the pilot were the ones belonging to "group 0", which are suitable for transporting infants from 0 to 9 months. However, the low performance of pushchairs was surprising because they were the most expensive items in the PSS, and renting them may have offered parents the opportunity to save money. On the other hand, pushchairs are a more emotional purchase (Thomsen and Sørensen 2006) - parents often see them as

\footnotetext{
${ }^{1}$ The number of times the products have been issued to parents
} 
fashion items that convey prestige. Pushchairs are also more likely than car seats to have a good second-hand value if sold on e.g., Ebay.

When ordering, customers were encouraged to exercise good stewardship of products and, importantly, of their packaging. However, one of the unforeseen side effects of the PSS mode of providing products was a rate of attrition of $8.8 \%$. In the REBUS project, attrition rate was defined as the number of car seats or pushchairs that were written off through damage or failure to return at the end of lease term (cf. Terry 2007). Consumers tended to retain car seats longer than six months and the manufacturer had to make considerable efforts to recover products, e.g., difficulty in contacting users to collect equipment at the end of the lease period - possibly exacerbated by users having paid a one-off rental fee in advance (see section 4.1). This might be addressed by a more flexible design of the service e.g., users having more freedom to decide the duration of use, seamless replacement of products and flexible payment methods, e.g., a monthly fee. There were wasted journeys if users were not available at the time of collection. Neither the manufacturer nor the provider had the resources to recover products in cases where users did not return them on demand. Therefore, in the open market, a high attrition rate might present a financial risk for providers and threaten the viability of a PSS, unless there was considerable investment in resources to recover products. Figure 3 summarizes the attrition rate.

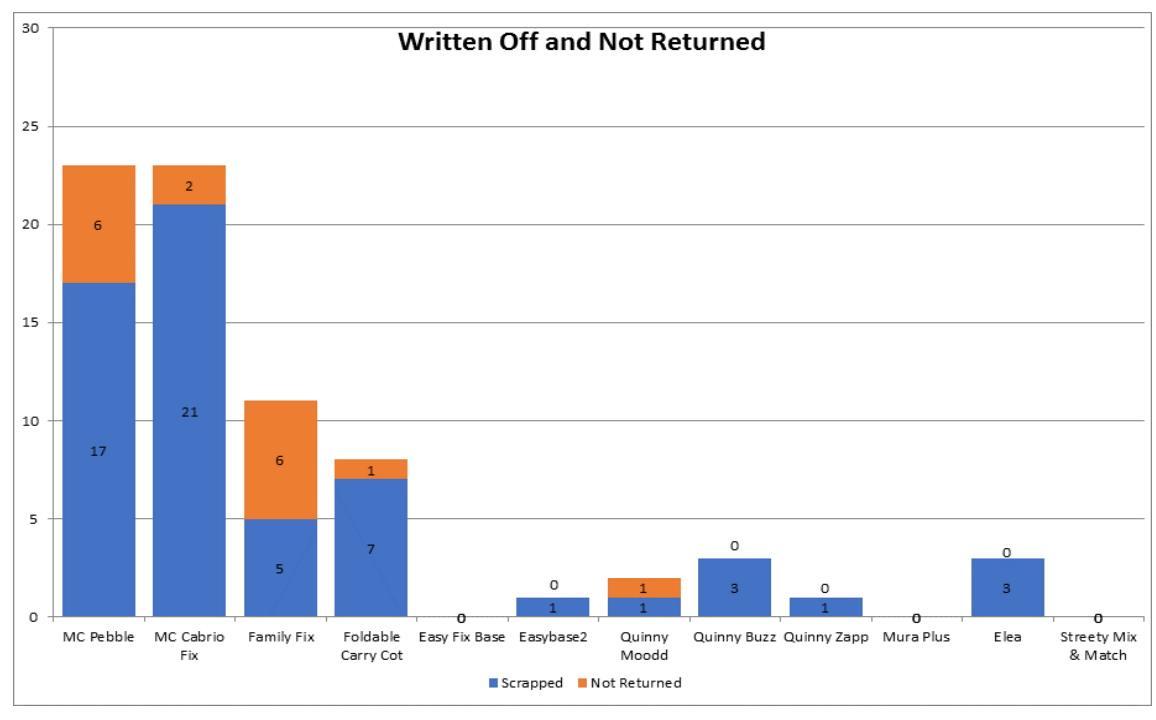

Figure 3 Attrition

This figure shows that a number of products were written off because they were returned in such condition that their refurbishment was considered too expensive and the number of products not returned by users. The number of types of products written off is in proportion with the number of each product type that was rented. It is possible that selecting users based on their trustworthiness (e.g., their credit ratings) could reduce attrition. 


\subsection{Capturing and mediating mutual learning}

This section focuses on insights that could inform launching the PSS in the open market. The research partners benefited from confidential learning in a protected environment. Discussions on the configuration of the service components of the PSS focused on two parameters, which were considered useful to shape a PSS where multiple products are offered for consumption, namely:

- Breadth: the number of customers who can be satisfied sequentially with the same item/material.

- Depth: the number of uses that can be obtained from a PSS for a given user across multiple product categories.

The manufacturer's managers claimed that depth is about "mining" a single user along their life cycle and managing the relationship with users whilst providing them with different types of products.

The experiment aimed at achieving multiple uses of the products to reap the benefits of resource efficiency and to ensure the financial viability of the PSS, by spreading costs across uses. A proportion of products achieved two uses. This included a few pushchairs see Figure 4. A small proportion of car seats were used three or four times. The project team had agreed a costs threshold for refurbishment to decide whether to refurbish products when these had been returned damaged. The refurbishing process was viable in the project because of its small scale. Because of funding limitations, it was not possible to design products specifically for PSS. 


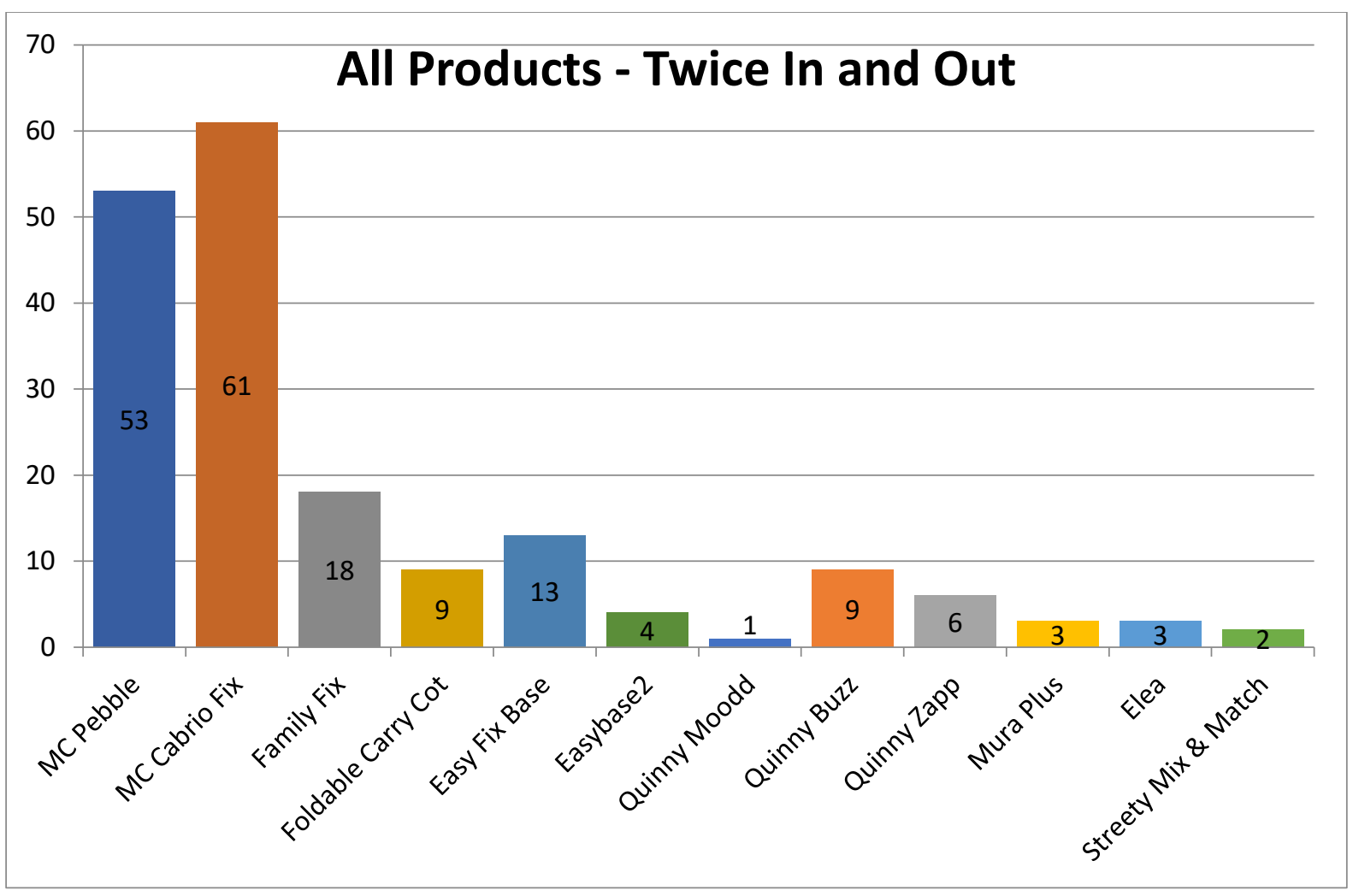

Figure 4 Products Used Twice

In order to make the PSS financially viable, multiple product rentals were considered more likely by focusing on a limited range of products, which would avoid a high cost of stock - for example by limiting the number of specialist models, such as pushchairs suitable for jogging or trekking. The consensus that emerged from the workshops is that a PSS in a competitive market should utilize standardized products, which would achieve economies of scale.

Products need be designed so that they can be cost effectively refurbished and with more effective recycling processes. Products should be of modular design with robust fabrics. For example, car seats covers are a major part of the cost of the seat and they make a major contribution to the attractiveness of the product. Most car seat covers on the market are not easy to remove, wash or recycle. If they were, they would be more suitable for a PSS. However, such PSS specific products would require considerable investment in tooling and labour intensive refurbishing and remanufacturing facilities with sufficient capacity, which would entail investment risks.

Connected to product refurbishment are the risks run by suppliers in respect of product liability. The refurbishing process is critical in this type of PSS and the manufacturer appreciated the need to keep control of the process in order to assure quality. Therefore, if the manufacturer scaled up the PSS, they might not wish to delegate refurbishment to other organizations that are local to customers or to allow refurbishment/repair by customers 
themselves. The downside of that would be the loss of the environmental benefits accruing from local refurbishment due to the product traveling shorter distances. To ensure correct usage of the product, customers who are supplied with refurbished products also need to be given the same product information as they would have been with a brand new product. Accordingly, a supplier would need a QA process - not only to make the product acceptable to consumers, but also to assure performance safety.

Logistics emerged as a key challenge for PSS design. Managers stated that transportation costs significantly affect viability. The need to package and repackage products as the provider delivers them to and collects them from users, adds to the complexity of logistics. Reusable packaging could contribute to keep costs down. The person-hours required to package and repackage products need to be factored into the costs of supplying them. Providers could perhaps outsource such logistics to local contractors. However, participants claimed that centralized logistics would be necessary for efficiency. Efficient logistics are essential for customer satisfaction. Workshop participants agreed that most consumer feedback was about product delivery, with negative feedback significantly associated with delivery problems.

The simplified LCA started from the notion that a conventional car seat requires 50.8, 11.6 and $3.5 \mathrm{~kg}$ of resources from the air, ground and water respectively. Table 2 compares the increase in resource use for each additional time car seats are acquired outright and by PSS, respectively. The greatest benefits of the PSS are for air and ground resources. Additionally, as mentioned above, reduction in resources per use may also contribute to diverting resources from disposal (depending on what happens to a conventionally acquired car seat at the end of life phase).

Table 2 Comparison of increase in resource use for each use of car seats

\begin{tabular}{|l|r|r|}
\hline $\begin{array}{l}\text { Resource use } \\
\text { increase }\end{array}$ & $\begin{array}{l}\text { Conventional Car } \\
\text { seat (\%) }\end{array}$ & $\begin{array}{l}\text { PSS Car seat } \\
(\%)\end{array}$ \\
\hline Air resources & 100 & 28.9 \\
\hline Ground resources & 100 & 37.0 \\
\hline Water resources & 100 & 96.7 \\
\hline
\end{tabular}

With respect to emissions, each conventional car seat results in $65 \mathrm{~kg}, 0.001 \mathrm{~kg}$ and $0.3 \mathrm{~kg}$ emissions to air, soil and water respectively. Table 3 compares increases in emissions each 
additional time car seats are acquired by conventional, outright acquisition and PSS respectively. The PSS provides significant reductions in emissions to air, ground and water.

Table 3 Comparison of increase in emissions for each use of car seats

\begin{tabular}{|l|r|r|}
\hline $\begin{array}{l}\text { Emissions use } \\
\text { increase }\end{array}$ & $\begin{array}{l}\text { Conventional Car } \\
\text { seat (\%) }\end{array}$ & $\begin{array}{l}\text { PSS Car seat } \\
(\%)\end{array}$ \\
\hline Emissions to Air & 100 & 29.9 \\
\hline Emissions to Ground & 100 & 22.5 \\
\hline Emissions to Water & 100 & 20.5 \\
\hline
\end{tabular}

The end impacts (arising from resource use and emissions) of the two ways of acquisition, and the benefits of PSS (the difference) are shown in Table 4. The most notable benefits were:

- Reduction in particulate matter, followed by acidification, photochemical ozone formation, climate change and eutrophication (terrestrial and marine).

- Reduction in use of plastics (especially polypropylene)

- Reduction in transport of new components to build car seats for conventional acquisition.

Table 4 Normalised impacts for conventional and PSS car seats (2 uses)

\begin{tabular}{|l|c|c|c|}
\hline Impact category & $\begin{array}{c}\text { Conventional } \\
(\%)\end{array}$ & PSS (\%) & Difference \\
\hline Climate change & 0.29 & 0.21 & -0.08 \\
\hline Ozone depletion & 0.77 & 0.77 & 0.00 \\
\hline Human toxicity, cancer effects & 0.03 & 0.03 & 0.00 \\
\hline $\begin{array}{l}\text { Human toxicity, non-cancer } \\
\text { effects }\end{array}$ & 0.22 & 0.19 & -0.03 \\
\hline Particulate matter & 1.65 & 0.83 & -0.82 \\
\hline Photochemical ozone formation & 0.37 & 0.25 & -0.12 \\
\hline Acidification & 0.42 & 0.30 & -0.12 \\
\hline Eutrophication terrestrial & 0.20 & 0.14 & -0.06 \\
\hline Eutrophication freshwater & 0.12 & 0.11 & -0.01 \\
\hline
\end{tabular}




\begin{tabular}{|l|c|c|c|}
\hline Eutrophication marine & 0.20 & 0.13 & -0.07 \\
\hline Ecotoxicity freshwater & 0.05 & 0.03 & -0.02 \\
\hline Resource depletion water & 0.10 & 0.10 & 0.00 \\
\hline $\begin{array}{l}\text { Resource depletion, mineral, } \\
\text { fossils and renewables }\end{array}$ & 0.04 & 0.03 & -0.01 \\
\hline
\end{tabular}

In general, participants agreed that if the PSS were to be implemented in the open market, management of relationships with consumers would present a considerable challenge, which would require investment in marketing. Most manufacturers of infant mobility products distribute their products through traditional distribution systems, such as specialist retailers. Participants commented that traditional retailers would be hostile to a large scale PSS as they would see it as unfair competition from their suppliers.

The small scale of the REBUS project meant that partners performed back and front office administration manually, with considerable costs. Large-scale implementation of the PSS would require automation of all these business processes, requiring considerable investment in processes and facilities.

\section{Discussion}

This paper has presented the REBUS project, a socio-technical experiment in a protected niche or 'safe space' (cf. Collins, 2020). The processes of shielding, nurturing and empowering socio-technical innovations theorized by Sengers et al. (2019) were in evidence in the activities described. The REBUS PSS was a resource efficient offering which presented opportunities to reuse refurbished products and recycle components at the end of life cycle. It was developed and promoted within the confines of the membership of the provider, which competitors could not access. The innovation was financially supported by DEFRA, a Department of the UK Government and research partners contributed in kind with skills and knowledge that are normally difficult and expensive to access (Cook et al. 2006). The University partner, an outsider to the world of infant mobility products, contributed a fresh perspective to sustainable innovation (cf. Van De Poel 2000). Within the niche, the research partners established new rules (cf. Schot and Geels 2008), such as the fit-andconform (Köhler et al. 2019) quality assurance process that reassured users when making the decision to rent refurbished car seats.

As the project was rooted in a protected niche but configured in a realistic fashion, it enabled the "piloting" of design and operation of the PSS by testing it in real life conditions (Argyris 
and Schön 1989). This allowed actors to address issues as they arose and to learn about usefulness and feasibility of the innovation in a competitive market before further resources were wasted by persisting with the implementation of something that promised little value added for the costs incurred. PSS innovations such as REBUS might not survive in the mainstream market environment (Ceschin 2013) and therefore work in protected niches is needed to predict the likely pressures a PSS might endure in a competitive environment.

The environmental benefits identified by the LCA seem to make the PSS worth pursuing, although, confirming Gottberg et al. (2009), these benefits may be less than some PSS literature have indicated, (e.g. Manzini and Vezzoli 2005). Furthermore, our findings identify hurdles to large scale implementation. An initial challenge to renting pre-used, refurbished infant mobility products to consumers is the quality assurance required to reassure users. The poor performance of pushchairs in the project questions whether that product is suitable for PSS. Some products may be less suitable than others to be supplied as remanufactured (cf. Michaud and Llerena's 2010). Secondly, refurbishing requires standardization, because the need to process many types of products would result in too high a level of complexity. However, focusing on a narrow product range may conflict with consumer requirements e.g., if they desire variants of products to meet their lifestyles - such as using pushchairs when jogging (Catulli et al. 2017). In addition to quality assurance (cf. Michaud and Llerena 2010), products need to be designed with better refurbishing characteristics (cf. Sinha et al. 2016), for example modular design and ease of disassembly. As products such as pushchairs have a 'fashion value' consumers may not find refurbished pushchairs attractive and this requires investigation. In the open market, consumers might distrust a PSS providing some types of refurbished products (Catulli 2012), because of fear of contagion (Bardhi and Eckhardt 2012). The current coronavirus pandemic is one of a range of catastrophes (Fineberg 2014) that could affect consumer trust in sharing products - and present providers with product liability implications. A further restraint on the design of a PSS in this market is the stringent regulations that govern the safety of infant products. The REBUS niche experiment limited the risk of product liability, which was a specific concern expressed in the final workshops. Product liability is an even greater issue with refurbished products. This makes a QA process essential for a PSS that involves refurbishing products (cf. Catulli and Reed 2017). The identification of product liability as such a key concern in a protected niche aids the planning of measures to protect manufacturers and providers if they plan to offer a PSS on the open market. However, while consumption within a socio-technical niche might be viable, implementing a PSS outside the niche might just be frustrated because of consumer distrust, fear of contagion or the unwillingness of suppliers to be subjected to greater risk. 
REBUS identified attrition as an inherent risk of providing a PSS. Early observation of attrition within a socio-technical niche anticipated the financial impact of such occurrence in the open market. Sinha et al. (2016) recommend improving loop efficiency and collection systems to maximise product recovery, which in turn would increase the viability of the PSS. However, our results suggest that this might not always be within the provider's control and may requires good faith on the consumers' part. Attrition is also connected with refurbishing, because the level of damage sustained by products determines whether products can be refurbished or not (Fargnoli et al. 2018) and, of course, products that are not returned cannot be refurbished. So, in reality, only some of the products supplied can actually be refurbished (Ibid.). Possibly, chipping and tracking products could be used to improve loop efficiency.

The implementation of the PSS within the niche minimised the legal implications of renting products. In the open market, most commercial PSS involving hiring of goods in the UK will need to factor in the cost of acquiring a CCL and the legal processes associated with hiring goods that fall within the regime of regulated consumer hire agreements. Indeed, sharing economy examples such as Uber and Airbnb have proved challenging for policy makers. In the language of the Multi-Level-Perspective, change in the socio-technical landscape, particularly in legislation (stretch-and-transform interventions), would be necessary to nurture such a PSS (cf. Geels and Kemp 2007).

One insight that deserves further discussion is the two parameters of breadth and depth of a PSS that may have implications for a PSS design (cf. Catulli et al. 2020). Breadth is important for a PSS' viability, as the income derived from it can cover the cost of a unit. For example, six people could rent a car sequentially in a given day. In PSS such as car sharing systems, this might require faster turnaround for cleaning and refuelling and this may mean redesigning service systems to perform these operations. Depth is about supplying the same users with additional or substitute products as their requirements change. For example, as infants grow, car seats suitable for older age groups can replace group 0 car seats. In this case, a stronger approach to product stewardship, associated with user education, as well as certified refurbishment and remanufacturing processes, might be important aspects. All this suggests that PSS involve more variables than just products and services, which creates the need for increased engagement by both providers and users (cf. Sopjani et al. 2020).

The applicability of the learnings gained in the socio-technical experiment should be treated with caution because the experimental approach is context specific and the results may not be easily transferable to the wider market (Heale 2003). Outside a socio-technical niche, the contributors to the delivery of the PSS may be difficult to co-ordinate. 
Direct and reverse logistics emerge as a challenge both because of the impact on customer satisfaction resulting from a poor product delivery service and the costs involved in collecting products. The managerial implications of this are that designers and providers of a use orientated PSS need to allocate sufficient resources to the logistics of the PSS. The importance of the role of users in delivering the service through product and package stewardship is another key challenge. Users' performance also affects logistics and product availability, as the attrition rates demonstrate. This may require a closely-knit relationship with users which, in a large scale PSS, may demand considerable resources and management time.

Collins (2020) warns that tensions between participants' expectations and learning opportunities in socio-technical experiments may lead participants to overlook learning and turn away from the innovation. This final factor, in conjunction with the one described above, means that not all niche innovations can be implemented in the market because partial learnings and resource limitations demonstrate lack of feasibility of large-scale implementation.

\section{Conclusions}

The analytical framework presented in this paper offers a promising template to manage socio-technical experiments within strategic niches, which seem to generate learning and strategic direction for the launch of sustainable innovations such as PSS in the open market. Indeed, the framework helped identify challenges to the launch of such PSS in the real world together with the associated risks.

If successful in the open market, a PSS offering refurbished infant mobility would offer considerable opportunities to enhance resource productivity and material recycling. However, the coronavirus pandemic and similar events may pose existential threats to PSS because of the reluctance of consumers to share products. Quality Assurance processes, including perhaps disinfection, may be a possible solution. An important research question is whether such QA process can really alleviate consumer concerns.

PSS seems to work for products with short duration of use. However, implementing this business model faces a number of challenges, as there are issues with financial viability due to attrition and achievable number of use cycles. These issues could prove to be a substantial disincentive for would-be PSS providers. Certainly, implementation would require security features, insurance and adequate financial provision. This type of PSS might be implemented with:

(1) products expressly designed for refurbishing 
(2) centralized facilities for refurbishment and other servicing with a high degree of automation

(3) direct contact with customers

(4) larger volumes and direct sales (not using a distributor).

Designers and strategists need do design improved recovery loops to collect products in sufficiently good state for refurbishment and quality assurance.

Understanding consumer credit and product liability laws is essential when designing a PSS. If policy makers desire the diffusion of PSS, they need to deliver education and information to businesses or possibly alter regulation, and a stretch-and-transform intervention to regulate some PSS offerings and the necessary QA for refurbished products. Research needs to explore the challenges to PSS represented by product liability, extended producer responsibility and attrition.

\section{References}

Argyris, C., and D. A. Schön. 1989. Participatory action research and action science compared. Am Behav Sci 32:612-623.

Bakker, S., and B. Budde. 2012. Technological hype and disappointment: lessons from the hydrogen and fuel cell case. Technology Analysis \& Strategic Management 24:549-563.

Bardhi, F., and G. M. Eckhardt. 2012. Access-Based Consumption: The Case of Car Sharing. Journal of Consumer Research 39:1-18.

Bergvall-Kåreborn, B., C. I. Eriksson, A. Ståhlbröst, and J. Svensson. 2009. A milieu for innovation : defining living labs.in K. R. E. Huizingh, S. Conn, M. Torkkeli, and I. Bitran, editors. ISPIM Innovation Symposium : 06/12/2009 - 09/12/2009.

Beton, A., D. Dias, L. Farrant, T. Gibon, Y. Le Guern, M. Desaxce, A. Perwueltz, and I. Boufateh. 2014. Environmental Improvement Potential of Textiles (IMPRO-Textiles. European Commission.

Booth, R. 2016. Uber drivers stage go-slow protest through central London. The Guardian. The Guardian, London,UK.

Brinkmann, S., and S. Kvale. 2015. Interviews - Learning the Craft if Qualitative Research Interviewing. SAGE, Los Angeles.

Caniëls, M. C. J., and H. A. Romijn. 2008. Strategic niche management: towards a policy tool for sustainable development. Technology Analysis \& Strategic Management 20:245-266.

Caniglia, G., N. Schäpke, D. J. Lang, D. J. Abson, C. Luederitz, A. Wiek, M. D. Laubichler, F. Gralla, and H. von Wehrden. 2017. Experiments and evidence in sustainability science: A typology. Journal of Cleaner Production 169:39-47.

Catulli, M. 2012. What Uncertainty? Further Insights on why consumers might be distrustful of product service systems. Journal of Manufacturing Technology Management 23:780-793.

Catulli, M., M. Cook, and S. Potter. 2017. Consuming use orientated product service systems: a Consumer Culture Theory perspective. Journal of Cleaner Production 141:1186-1193.

Catulli, M., and N. Reed. 2017. A Personal Construct Psychology based investigation into a Product Service System for renting pushchairs to consumers Business Strategy and the Environment.

Catulli, M., N. Reed, J. Tzilivakis, and A. Green. 2020. Extending the Life of Infant Mobility Products: Implementing a Product Service System: Report on DEFRA ABR112 (Project EV0534)/ Reengineering Business for Sustainability., Department for Environment, Food and Rural Affairs (Defra, London, UK. 
Ceschin, F. 2013. Critical factors for implementing and diffusing sustainable product-Service systems: insights from innovation studies and companies' experiences. Journal of Cleaner Production 45:74-88.

Cherubini, S., G. lasevoli, and L. Michelini. 2015. Product-service systems in the electric car industry: critical success factors in marketing. Journal of Cleaner Production 97:40-49.

Collins, B. 2020. "It's not talked about": The risk of failure in practice in sustainability experiments. Environmental Innovation and Societal Transitions 35:77-87.

Cook, M. B., T. A. Bhamra, and M. Lemon. 2006. The transfer and application of Product Service Systems: from academic to UK manufacturing firms. Journal of Cleaner Production 14:14551465.

Cova, B., and V. Cova. 2002. Tribal Marketing: The tribalization of society and its impact on the conduct of marketing. European Journal of Marketing 36:595-620.

Dibdiakova, J., and V. Timmermann. 2014. Life cycle assessment on cotton and viscose fibres for textile production.in N. F. a. L. I. (NFLI), editor. COST FP1205: Innovative applications of regenerated wood cellulose fibres, Bangor, United Kingdom.

ecarclub.co.uk. 2020. Customer Information on the Coronavirus. ecarclub.co.uk.

Fargnoli, M., F. Costantino, G. Di Gravio, and M. Tronci. 2018. Product service-systems implementation: A customized framework to enhance sustainability and customer satisfaction. Journal of Cleaner Production 188:387-401.

Fineberg, H. V. 2014. Pandemic Preparedness and Response - Lessons from the H1N1 Influenza of 2009. The New England Journal of Medicine 370:1335.

Geels, F. W. 2002. Technological transitions as evolutionary reconfiguration processes: a multi-level perspective and a case-study. Research Policy 31:1257-1274.

Geels, F. W. 2011. The multi-level perspective on sustainability transitions: Responses to seven criticisms. Environmental Innovation and Societal Transitions 1:24-40.

Geels, F. W., and R. Kemp. 2007. Dynamics in socio-technical systems: Typology of change processes and contrasting case studies. Technology in Society 29:441-455.

Geels, F. W., and J. Schot. 2007. Typology of sociotechnical transition pathways. Research Policy 36:399-417.

Glasson, J. B., E. M. L. Chang, and J. W. Bidewell. 2008. The value of participatory action research in clinical nursing practice. International Journal of Nurseing Practice 14:34-39.

Gottberg, A., P. J. Longhurst, and M. Cook. 2009. Exploring the potential of Product Service Systems to achieve household waste prevention on new housing developments in the UK. Waste Management \& Research 0:1-8.

Harrabin, R. 2020. Coronavirus: Transport usage will change after lockdown. Bbc News. BBC.

Haward, M. 2018. Plastic pollution of the world's seas and oceans as a contemporary challenge in ocean governance. Nature Communications 9:667.

Heale, G. 2003. Applying theory to practice: an action research resource pack for professionals. Reliability Studies 6:4-14.

Hern, A., and G. Topham. 2018. Investors lured by figures that don't relate to the real world. The Guardian. The Guardian Plc, London.

Hoogma, R., R. Kemp, J. Schot, and B. Truffer. 2002. Experimenting for Sustainable Transport - The approach of Strategic Niche Management. Spon Press, London.

IPCC. 2006. IPCC Guidelines for National Greenhouse Gas Inventories. Prepared by the National Greenhouse Gas Inventories Programme.

JRC. 2016. European Platform on Life Cycle Assessment: European reference Life Cycle Database. . European Commission Joint Research Centre (JRC) Website.

Kemp, R., J. Schot, and R. Hoogma. 1998. Regime shifts to sustainability through processes of niche formation: The approach of strategic niche management. Technology Analysis \& Strategic Management 10:175-198. 
Köhler, J., F. W. Geels, F. Kern, J. Markard, E. Onsongo, A. Wieczorek, F. Alkemade, F. Avelino, A. Bergek, F. Boons, L. Fünfschilling, D. Hess, G. Holtz, S. Hyysalo, K. Jenkins, P. Kivimaa, M. Martiskainen, A. McMeekin, M. S. Mühlemeier, B. Nykvist, B. Pel, R. Raven, H. Rohracher, B. Sandén, J. Schot, B. Sovacool, B. Turnheim, D. Welch, and P. Wells. 2019. An agenda for sustainability transitions research: State of the art and future directions. Environmental Innovation and Societal Transitions 31:1-32.

Laurenti, R., J. Singh, R. Sinha, J. Potting, and B. Frostell. 2015. Unintended environmental consequences of improvement actions : A qualitative analysis of systems' structure and behavior. Systems research and behavioral science.

Leach, M., I. Scoones, and A. Stirling. 2010. Governing epidemics in an age of complexity: Narratives, politics and pathways to sustainability. Global Environmental Change 20:369-377.

Lewin, K. 1947. Frontiers in Group Dynamics. 1:143-153.

Loorbach, D., and R. van Raak. 2006. Strategic Niche Management and Transition Management: different but complementary approaches. DRIFT, Erasmus University Rotterdam. Discussion Paper.

Manzini, E., and C. Vezzoli. 2005. Product-Service Systems and Sustainability. UNEP, Milano.

Michaud, C., and D. Llerena. 2010. Green Consumer Behaviour: and Experimental Analysis of Willingness to Pay for Remanufactured Products. Business Strategy and the Environment.

Miles, M., and M. A. Huberman. 1994. Qualitative Data Analysis. SAGE, California, US.

Mont, O. K. 2002. Clarifying the concept of Product Service System Journal of Cleaner Production 10:237-245.

Mont, O. K., C. Dalhammar, and N. Jacobsson. 2006. A new business model for baby prams based on leasing and product remanufacturing. Journal of Cleaner Production 14:1509-1518.

OFT. 2008. Do You Need a Credit Licence?in O. o. F. Trading, editor. Office of Fair Trading, London.

Pidd, H. 2018. Manchester put on warning after bikeshare vandalism. The Guardian. The Guardian Plc, London.

Plastics Europe. 2014. Eco-profiles and Environmental Product Declarations of the European Plastics Manufacturers. PlasticsEurope AISBL, Brussels, Belgium.

Sala, S., Benini, L., Mancini, L. and Pant, R. . 2015. Integrated assessment of environmental impact of Europe in 2010: data sources and extrapolation strategies for calculating normalisation factors. International Journal of Life Cycle Assessment 20:1568-1585.

Schmidt-Costa, J. R., M. Uriona-Maldonado, and O. Possamai. 2019. Product-service systems in solar PV deployment programs: What can we learn from the California Solar Initiative? Resources, Conservation and Recycling 140:145-157.

Schot, J., and F. W. Geels. 2008. Strategic niche management and sustainable innovation journeys: theory, findings, research agenda, and policy. Technology Analysis \& Strategic Management 20:537-554.

Sengers, F., A. J. Wieczorek, and R. Raven. 2019. Experimenting for sustainability transitions: A systematic literature review. Technological Forecasting and Social Change 145:153-164.

Shen, L., and M. K. Patel. 2008. Life cycle assessment of man-made cellulose fibres.

Sinha, R., R. Laurenti, J. Singh, M. E. Malmström, and B. Frostell. 2016. Identifying ways of closing the metal flow loop in the global mobile phone product system: A system dynamics modeling approach. Resources, Conservation and Recycling 113:65-76.

Sopjani, L., M. Hesselgreen, S. Ritzen, and J. Janhager Stier. 2017. Co-creation with diverse actors for sustainability innovation.in 21st International Conference on engineering Design, ICED17. Vancouver ICED, Vancouver, Canada.

Sopjani, L., J. J. Stier, M. Hesselgren, and S. Ritzén. 2020. Shared mobility services versus private car: Implications of changes in everyday life. Journal of Cleaner Production 259:120845.

Sundin, E., M. Lindahl, and W. ljomah. 2009. Product design for product/service systems - Design experiences from the Swedish industry. Journal of Manufacturing Technology Management 30:723-753. 
Susur, E., A. Hidalgo, and D. Chiaroni. 2019. A strategic niche management perspective on transitions to eco-industrial park development: A systematic review of case studies. Resources, Conservation and Recycling 140:338-359.

Terry, N. 2007. Assessing Instruction Modes for Master of Business Administration (MBA) Courses. Journal of Education for Business 82:220-225.

Thomsen, T. U., and E. B. Sørensen. 2006. The First Four-wheeled Status Symbol: Pram Consumption as a Vehicle for the Construction of Motherhood Identity. Journal of Marketing Management 22:907-927.

Tukker, A. 2015. Product services for a resource-efficient and circular economy - a review. Journal of Cleaner Production 97:76-91.

Turley, D. B., M. Horne, R. S. Blackburn, S. E., S. R. Laybourn, J. E. Copeland, and J. Harwood. 2008. The role and business case for existing and emerging fibres in sustainable clothing. Department for Environment, Food and Rural Affairs (Defra), London, UK.

UniversityofHertfordshire. 2020. Smart Mobility Unit.

Van De Poel, I. 2000. On the Role of Outsiders in Technical Development. Technology Analysis \& Strategic Management 12:383-397.

Vezzoli, C., F. Ceschin, J. C. Diehl, and C. Kohtala. 2015. Why have 'Sustainable Product-Service Systems' not been widely implemented? Meeting new design challenges to achieve societal sustainability. Journal of Cleaner Production 35:288-290.

Vilches, A., A. Garcia-Martinez, and B. Sanchez-Montañes. 2017. Life cycle assessment (LCA) of building refurbishment: A literature review. Energy and Buildings 135:286-301.

Wellsandt, S., E. Nabati, T. Wuest, K. A. Hribernik, and K.-D. Thoben. 2016. A survey of product lifecycle models: towards complex products and service offers. International Journal of Product Lifecycle Management (IJPLM) 9.

White, A. L., M. Stoughton, and L. Feng. 1999. Servicizing: The Quiet Transition to Extended Product Responsibility. U.S. Environmental Protection Agency - Office of Solid Waste.

Zademach, H.-M., and A.-K. Musch. 2018. Bicycle-sharing systems in an alternative/diverse economy perspective: a sympathetic critique. Local Environment 23:734-746. 